\title{
AMBIENT NOISE HORIZONTAL-TO-VERTICAL SPECTRAL RATIO FOR ASSESSING SITE EFFECTS IN URBAN ENVIRONMENTS: THE CASE OF THESSALONIKI CITY (NORTHERN GREECE)
}

Panou A.A. ${ }^{1,2}$, Theodulidis N. ${ }^{2}$, Hatzidimitriou P.M. ${ }^{1}$, Papazachos C.B. ${ }^{1}$, and Stylianidis $\mathrm{K}^{3}$

${ }^{1}$ Geophysical Laboratory, School of Geology, Aristotle University of Thessaloniki, PO Box 352-1, 54124, Thessaloniki, apanou@lemnos.geo.auth.gr,_costas@lemnos.geo.auth.gr, takis@lemnos.geo.auth.gr

${ }^{2}$ Institute of Engineering Seismology and Earthquake Engineering, P.O. Box 53 Foinikas, GR55102, Thessaloniki, ntheo@itsak.gr

${ }^{3}$ Laboratory of Reinforced Concrete Structures, Department of Civil Engineering, Aristotle University of Thessaloniki, PO Box 482, GR-54124, Thessaloniki, kcstyl@civil.auth.gr

\section{ABSTRACT}

250 ambient noise measurements were performed in a dense grid (about $150 \mathrm{~m} \times 150 \mathrm{~m}$ ) covering the historical center of the city of Thessaloniki (Northern Greece), that was strongly affected by the 20/6/1978 $(M=6.5)$ damaging earthquake. The data were processed using the method of horizontal-to-vertical (H/V) spectral ratio (Nogoshi and Igarashi, 1971; Nakamura, 1989). In order to evaluate diurnal and seasonal variation (summer - winter) of the ambient noise $\mathrm{H} / \mathrm{V}$ spectral ratio, systematic measurements were performed in eight sites. The fundamental frequency (fo) and the corresponding $\mathrm{H} / \mathrm{N}$ amplitude level (Ao) from the ambient noise $\mathrm{H} / \mathrm{V}$ spectral ratio for each site were calculated. Spatial interpolation of the fundamental frequency (fo) and the corresponding $\mathrm{H} / \mathrm{V}$ amplitude level $(\mathrm{Ao})$ was attempted between all points and respective contour maps were produced.

Diurnal variation of the ambient noise H/V spectral ratio showed that it is preferable to perform measurements during the calm hours of a day, when manmade noise is relatively low. However, no systematic seasonal fluctuation effect on the ambient noise $\mathrm{H} / \mathrm{V}$ spectral ratio was identified for the city of Thessaloniki. Contour maps of both fundamental frequency (fo) and corresponding $\mathrm{H} / \mathrm{V}$ amplitude level (Ao) were compared versus the macroseismic data of the 1978 earthquake (Leventakis, 2003), as well as with related geological (IGME, 1978) and geotechnical (Anastasiadis et al., 2001) studies for the same area. Damage distribution due to 20/6/1978 earthquake (Penelis et al., 1985) was also converted to EMS_98 (European Macroseismic Scale, 1998). For seventy buildings, made of reinforced concrete, we have also compared the obtained results with the dynamic amplification of the buildings (Ubuilding) at the fundamental soil frequency (fo). The results encourage the use of ambient noise measurements along with the $(H / V)$ spectral ratio technique as a nonexpensive and fast tool in microzonation studies to be carried out in urban environments.

\section{INTRODUCTION}

A more and more common approach for the characterization of site response in urban environments involves the use of the H/N spectral ratio of ambient noise recordings. Ambient noise is low amplitude vibrations of soil generated by natural disturbances such as wind, sea tides or of manmade origin such as traffic, industrial machinery, household appliances etc. The spectral ratio of horizontal to vertical component of ambient noise [hereafter HVSR_AM] usually shows a peak, which indicates the fundamental frequency of the investigated site (Nogoshi and Igarashi, 1971; Nakamura, 1989). The reliability of this method has been studied both numerically and experimentally. Several researchers (among which Field and Jacob, 1993; Lachet and Bard, 1994; Lermo and Chávez-Garcia, 1994a) have theoretically supported the H/V spectral ratio technique through nu- 
merical simulations showing that synthetics obtained by randomly distributed near surface sources lead to H/V spectral ratios sharply peaked around the fundamental S-wave frequency, whenever the surface layers exhibit a sharp impedance contrast with the underlying stiffer formations. A large number of observational studies have been performed to experimentally establish the credibility of the method (Ohta et al., 1978; Mucciarelli, 1998; Rodriguez and Midorikawa, 2002 among others). A complete review of modern applications of ambient noise measurements for site effect estimation can be found in Bard (1999).

The ambient noise $\mathrm{H} / \mathrm{V}$ spectral ratio technique is less time consuming and much cheaper than other classical geophysical site investigations. Although the seismological community generally agrees that the $H / V$ spectral ratio of ambient noise gives reliable results in terms of fundamental frequency, the method has been developed mainly empirically. The aim of this paper is to examine the reliability and the validity of the ambient noise technique in the downtown district of the city of Thessaloniki (Northern Greece) (left part of Figure1).

\section{COMPARISON OF HVSR_AM WITH RECEIVER FUNCTIONS}

In order to compare H/V spectral ratios of ambient noise recordings with results from other techniques traditionally used for site effect studies, ambient noise measurements were carried out at ten sites within the city of Thessaloniki (right part of Figure 1). The equipment used comprises the Cityshark 24-bits recorder (Chatelain et al., 2000) coupled with a Lennartz 3D/5s velocimeter sensor. At each site ambient noise data were continuously recorded for at least $10 \mathrm{~min}$ and as long as $40 \mathrm{~min}$. The data were sampled at $100 \mathrm{~Hz}$ and the average noise $\mathrm{H} / \mathrm{V}$ spectral ratios of each recording were calculated with the SEISAN_7.2 (Havskov and Ottemöller, 2000) separately for each horizontal component.

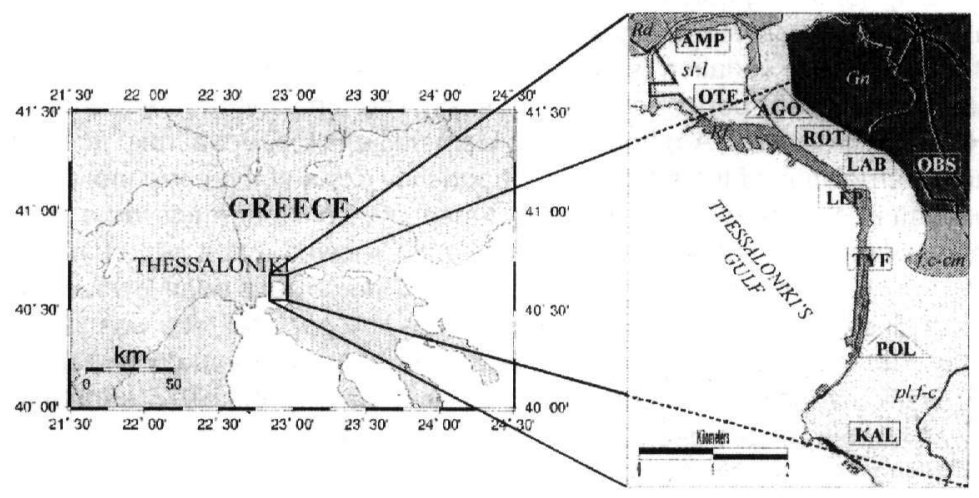

Figure 1. Left part: Location of the city of Thessaloniki, Northern Greece. Right part: Map of the region of Thessaloniki with the main geological units (Rf: Debris; Rd: River-torrential deposits with thickness up to 10m; sl-1: Quaternary silty layers; f,c-cm: Pleistocene undivided layers with thickness up to $40 \mathrm{~m}$; pl,f-c: Neogene deposits; $\mathrm{Gn}$ : Gneiss) and the location of the sites for which weak and strong motion earthquake data were available (IGME, 1978)

At the same ten sites, Reftek stations had been installed between 25 November 1993 and 19 February 1994 (Lachet et al., 1996 [La]; Triantafyllidis et al., 1999 [Tr]) and recorded several local and regional events. Two types of sensors were used in each site: an accelerometer Guralp CMG5 [Tr] and a broadband velocimeter Guralp CMG40 ( $T=20 \mathrm{sec}$ ) [La] in eight sites (rectangulars in Fig. 1) or alternatively a short-period Mark Product $L 22(T=0.5 \mathrm{sec})$ in other two sites (triangles in Fig. 1).

In Figure 2 the variation with frequency of the average noise H/V spectral ratio for the EW component in comparison with the corresponding mean value from [La] and [Tr] receiver functions using earthquake recordings, is shown. In general, the results show that there is a similarity in fundamental frequency and overall shape of the H/V spectral ratios in all examined sites between noise $\mathrm{H} / \mathrm{V}$ spectral ratio and earthquake receiver functions. 


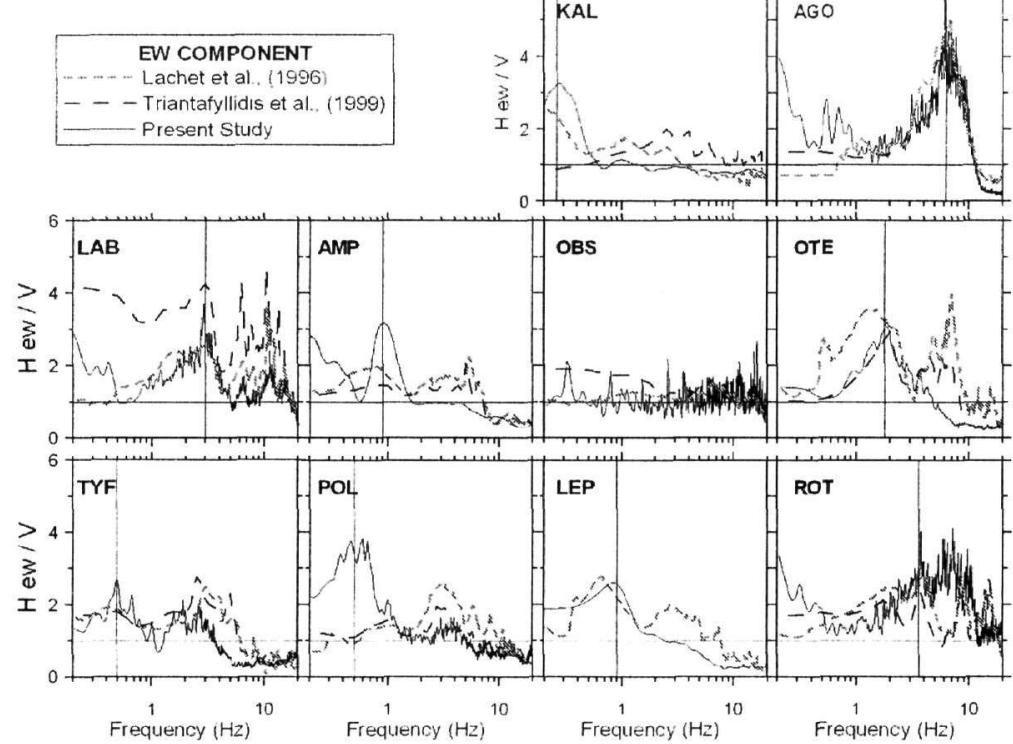

Figure 2. Comparison of the HVSR_AM obtained in the present study (EW component: black solid line) with earthquake receiver functions at the same sites.

A systematic difference between the HVSR_AM and the corresponding receiver functions of [Tr] in the low frequency band $(f<1 \mathrm{~Hz})$ was observed, while a good agreement is found in higher frequencies. However, at site LAB a significant difference between the HVSR_AM and accelerometer data, is observed. At the site LEP, [Tr] receiver function was not estimated, because noise level at this site was very high, producing a poor signal to noise ratio. On the other hand, the very good agreement of HVSR_AM with [La] receiver functions, based on velocimeter data, is evident for almost all sites for the entire frequency range. Such an agreement has been also noted by ChávezGarcia and Cuenca (1996), Toshinawa et al. (1997) and Ojeda and Escallon (2000), among others. However, at the site POL differences in low frequencies are most probably due to the L22 sensor ( $T 0=0.5 \mathrm{sec}$ ), used in [La]. Their results are less reliable for frequencies below $2 \mathrm{~Hz}$, due to relatively poor response of L22 sensor in this frequency range. At the ROT site ambient noise measurements were performed about $30 \mathrm{~m}$ to the east far from those of [La] and [Tr], probably explaining the observed difference in a narrow frequency band between $5 \mathrm{~Hz}$ to $8 \mathrm{~Hz}$. At the site OTE although the agreement between the three methods are satisfactory, the second harmonic that clearly could be seen in the H/N receiver functions does not appear in the HVSR_AM. Nevertheless, the agreement between the three independent estimations may be considered as satisfactory, supporting the idea that ambient noise measurements can be used as a reliable measure of site effects in the city of Thessaloniki.

\section{DIURNAL AND SEASONAL EVALUATION OF HVSR_AM}

In order to study the diurnal and seasonal variation of HVSR_AM in the city of Thessaloniki, we recorded five minutes of ambient noise data every one-hour for two consecutive days at eight sites (Figure 3 ) in the historical center of the city of Thessaloniki. These sites are spread in the historical center of the city where dense ambient noise measurements were made and display a variety of geological conditions (Anastasiadis et al., 2001). The ambient noise recordings are classified into five time-categories: morning (05:00am-9:00am GMT), midday (10:00am-13:00pm GMT), afternoon (14:00pm-16:00pm GMT) (with market closed), evening (17:00pm-21:00pm GMT) (with market closed) and night (22:00pm-04:00am GMT). The average noise H/V spectral ratios of each category were calculated separately for each horizontal component. 


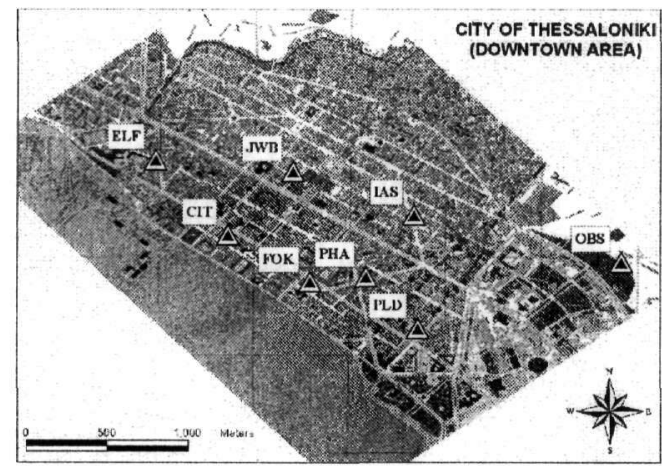

Figure 3. Location of the eight sites of the Thessaloniki downtown area, where diurnal and seasonal ambient noise measurements were performed.

Figure 4 illustrates the diurnal variation of the average H/VSR_AM obtained for all time categories for each site. As it is observed in Fig. 4, at every site diurnal variations of the H/VSR_AM in terms of shape are similar in both horizontal components, except for site JWB where a sharp peak appears in NS direction around $3 \mathrm{~Hz}$. In all sites, variations in amplitude level of the H/VSR_AM are present. Such a variation has been also observed by other researchers (e.g. Teves-Costa et al., 1996; Navarro et al., 2001; Alfaro et al., 2001). Furthermore, for the majority of the sites the amplitude level of the fundamental frequency during the morning time period is smaller than for the nighttime period. This is particularly apparent at sites PLD, FOK, ELF and PHA. These sites are located in buildings close to main streets of the center of Thessaloniki, where traffic peak occurs between 06:00am-14:00am GMT (Tsilingiridis et al., 2002). This is a strong indication that H/VSR_AM is influenced by manmade activities during working hours, as has been noted in a number of relevant studies (e.g. Fyen, 1990; Gitterman et al., 1996; Milana et al., 1996). In addition, Bahavar and North, (2002) also observed that high-frequency levels are higher during local daytime than at night-time.
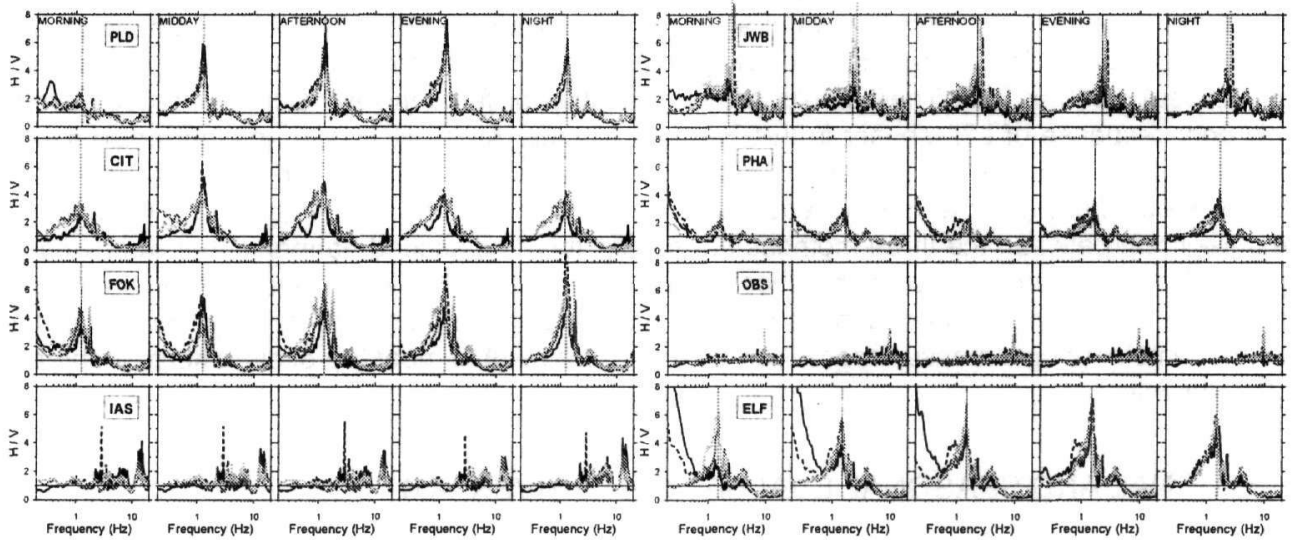

Figure 4. Comparison of the HVSR_AM between summer (Hew/V: black line; Hns $N$ : black dashed line) and winter period (HewN: grey dark line; Hns $N$ : grey light line).

The seasonal variation of the average H/VSR_AM is also illustrated in Figure 4. As can been seen, the shape of the HVSR_AM, at all sites shows a noticeable stability both in fundamental frequency and amplitude level, especially during the evening and night measurements. In site IAS a sharp peak at approximately $3 \mathrm{~Hz}$ appears in the summer time measurements but is not apparent in the winter. This may be due to an unknown manmade noise, present only during summer time 
measurements. Furthermore, the fundamental frequency in all sites is practically constant, regardless of the season that the measurements were performed, as has also been observed by other researchers (Duval et al. 1995, Suzuki et al. 1995, Bour et al. 1998, Delgado et al. 2000a, LeBrun et al. 2001).

\section{DATA ACQUISITION/PROCESSING AND RESULTS}

Ambient noise measurements took place in the downtown district of the city of Thessaloniki (Northern Greece) with a measurement grid (about $150 \mathrm{mX150m}$ ) and 250 measurements were carried out (Figure 5). The records were preformed from Monday to Friday either during evening period (18:00pm-22:00pm GMT with closed market) or during night period (23:00pm-05:00am GMT). A GPS system provided the geographic position of each measurement point. Ohta et al., (1978) have suggested at least a 10-to-20-min observation at a point in order to get a record good enough for analysis. In the experiment, the recording system operated continuously for $20 \mathrm{~min}$ with sample rate of $100 \mathrm{~Hz}$.
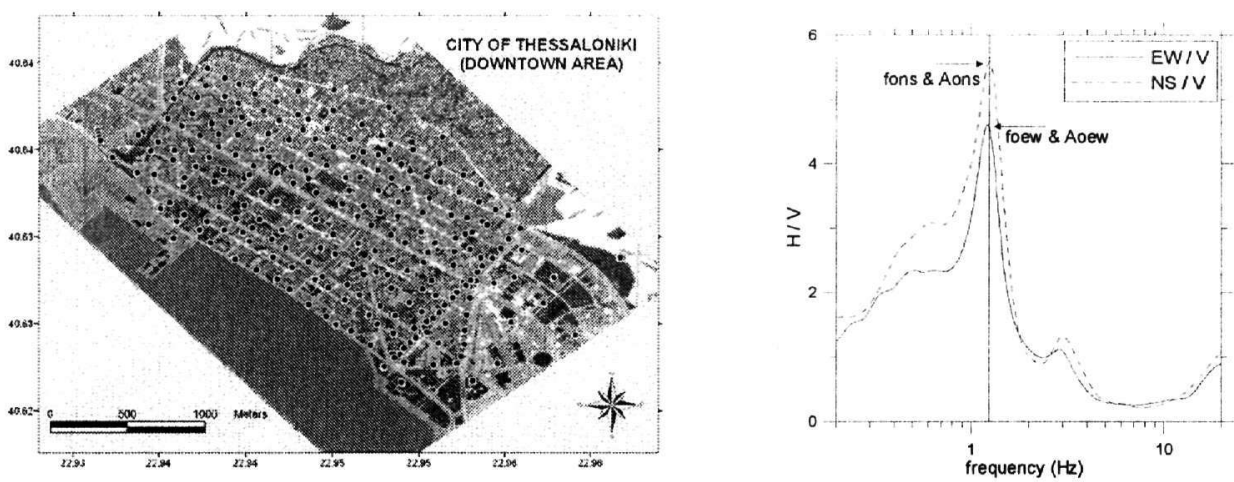

Figure 5. Location of ambient noise measurements in the downtown district of the city of Thessaloniki.

Figure 6. Plot of the average HVSR versus frequency.

Ambient noise data were processed in two stages. First, for each ambient noise recording, a number of windows, having a duration of $20 \mathrm{sec}$ each, were selected using the 'window selection' module of the JSESAME software (SESAME project, 2003), in order to exclude portions with forbiddingly large amplitudes or spikes, as has been suggested by Duval et al., (2003). Using the 'H/V processing' module of the JSESAME software, the following steps were applied: (a) computation of Fourier spectra in all three components (E-W, N-S, Vertical), (b) offset correction, (c) application of a cosine taper, (d) smoothing of the Fourier amplitude spectra by a Konno-Ohmachi algorithm (Konno and Ohmachi, 1998). For each point the horizontal record spectrum was divided by the vertical one separately for the two horizontal components, in order to detect any significant difference between them, and the EWIV and NS/V spectral ratio was obtained. The second step consists of plotting EW/V and NS/V spectral ratio versus frequency.

Each measurement point provides a spectral ratio and enables an estimation of the fundamental frequency (foew and fons) and the corresponding $H / V$ amplitude level (Aoew and Aons) at the site studied. A characteristic example is shown in Figure 6, where the HVSR_AM of EW (continuous line) and NS (dashed line) versus frequency are plotted. Although the foew has practically the same value with the fons, the Aoew and Aons are not the same for all our points, as it were In diurnal measurements. Thus, the average value of the fundamental frequency (fo) is used hereafter in the present study but for the amplitude level we used both Aoew and Aons.

The spatial interpolation of the fundamental frequencies and of the corresponding $H / V$ amplitude level of the spectral resulted in the maps presented in figures (7) and (8).

As it is illustrated in Figure 7 (left part), the low values of the fundamental frequency appear near the coastline while generally the fundamental frequencies decrease from north-east to southwest. This is consistent with the thickening of the alluvial deposits in this direction (Anastasiadis et 
al., 2001), as it is shown in right part of the same Figure. Such an observation has been also observed by other researchers (e.g. Delgado et al., 2000b; Parolai et al., 2002).
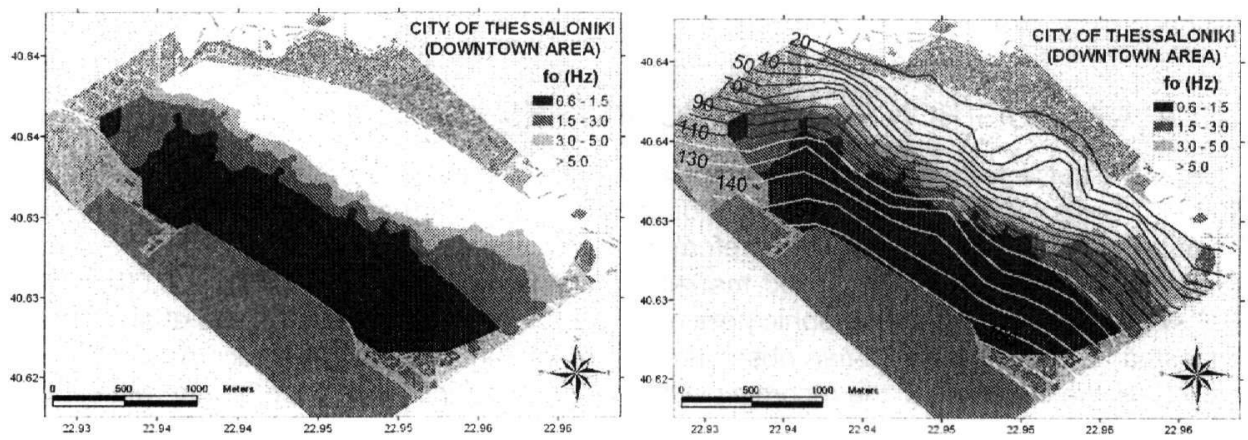

Figure 7. Left part: Contour map of the fundamental frequencies (fo). The categories are shown with different color symbols. Right part: Contour map of the fundamental frequencies (fo). The categories are shown with different color symbols. The lines represent the depth of the bedrock in meters (Anastasiadis et al., 2001).
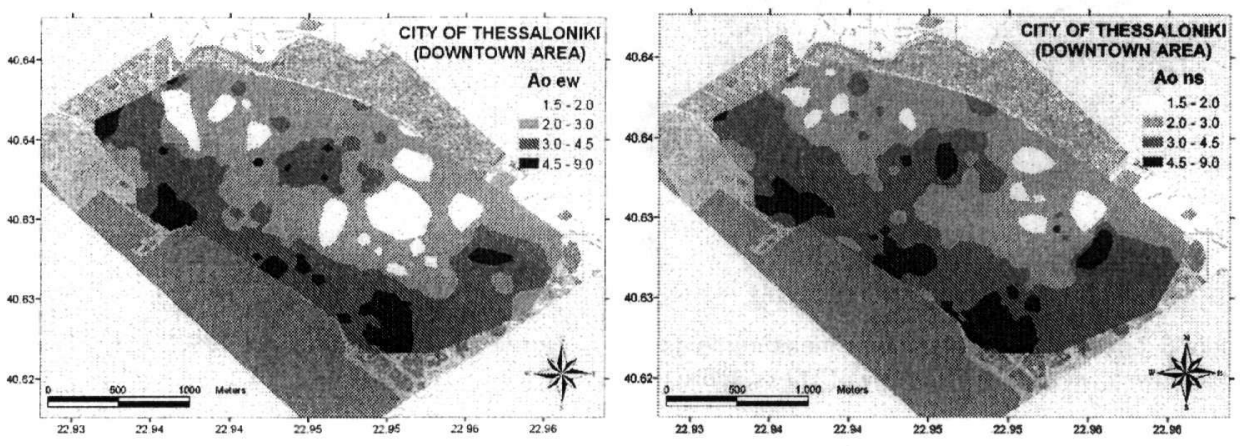

Figure 8. Contour map of the $\mathrm{H} N$ amplification level (Ao) at fundamental frequencies (Left part: north-south component, Right part: east-west component). The categories are shown with different color symbols.

Figure 8 shows the contour maps that were calculated from Aoew (left part) and Aons (right part) $H / V$ amplitude level. Although there are discrepancies between those maps, the zone in the north-east amplifies the ground motion less than that in the south-west in both of them. This results are consistent with the transition of the fundamental frequencies and the thickening of the alluvial deposits in this direction as well.

\section{COMPARISON WITH OBSERVED INTENSITIES}

To check the ability of the applied method to correlate a preliminary amplification zonation in the city of Thessaloniki, we compared our results with macroseismic data of the 1978 earthquake sequence in terms of MSK intensity data. Irregular damage distribution has been ascribed to local geology conditions as the city's subsoil varies significantly.

Figure 9 shows the contour maps of the fundamental frequency (fo) and of the maximum amplification (Aoew) of the H/V spectral ratio observed at each site, on which are superposed the isoseismal curves for four intensity levels defined by Leventakis (2003). We observe a clear overall correlation between them.

The quantification of the previous maps is shown in Figure 10. The higher levels of intensity were observed at sites with low fundamental frequency and correspondingly high $\mathrm{H} / \mathrm{N}$ amplitude level, while low levels of intensity were observed at sites with high fundamental frequency and cor- 
respondingly low H/V amplitude level. Despite the observed scatter, the comparison between the observed Intensity of the 1978 earthquake, with the fundamental frequency (fo) and the corresponding H/V amplitude level (Aoew and Aons), reveals a satisfactory correlation.
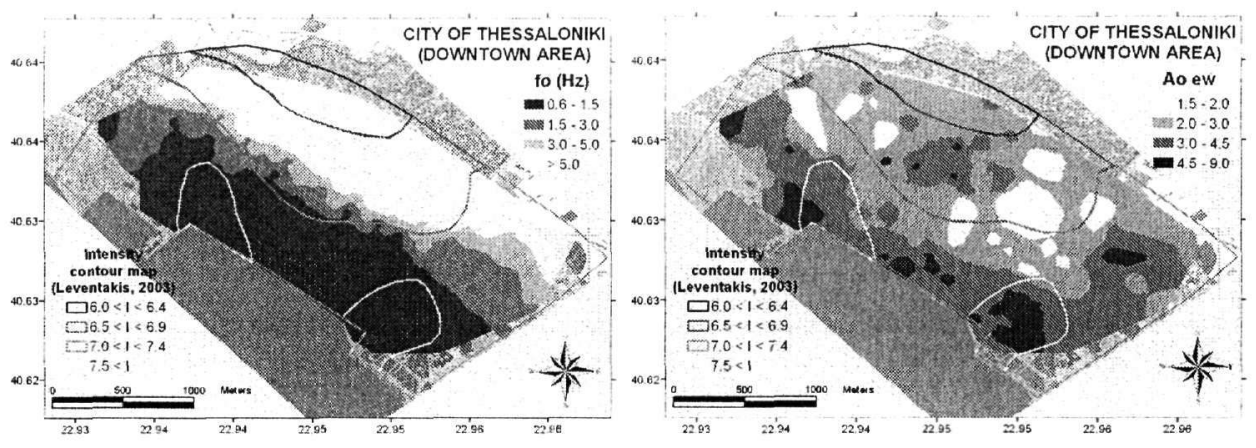

Figure 9. Comparison of the fundamental frequencies (fo) (left part) and the HN amplitude level (Aoew) (right part) at fundamental frequencies, with the Isoseismal intensity curves (Leventakis, 2003) from the 1978 ThessaIoniki Earthquake. The categories are shown with different color symbols.

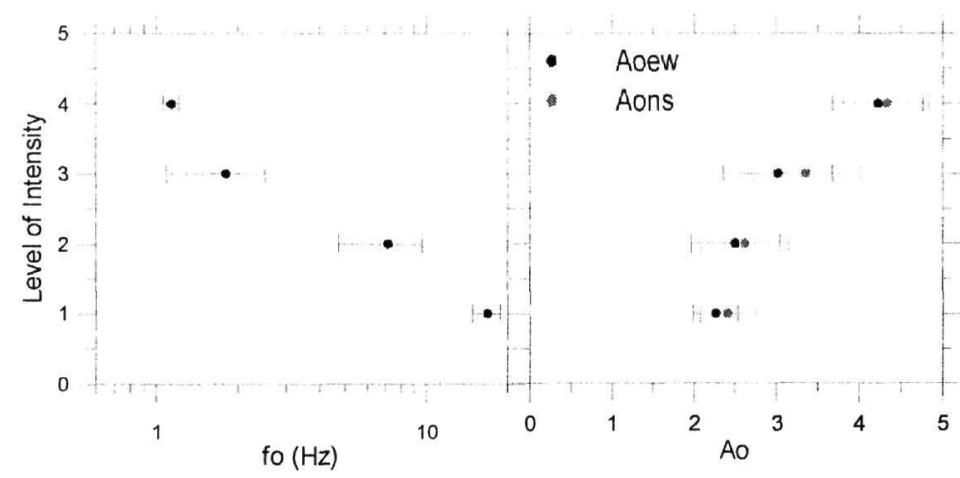

Figure 10. Correlation between the fundamental frequency (left part) and the corresponding $\mathrm{H} N$ amplitude level (Ao ew:balck dots; Aons: grey dots) (right part), with Isoseismal Intensities (1: $6.0<1<6.4,2: 6.5<1<6.9,3$ : $7.0<1<7.4,4: 7.5<1$; Leventakis, 2003) from the 1978 Thessaloniki Earthquake.

The damage distribution of the 1978 earthquake observed by Penelis et al. (1985) was converted to EMS_98 (European Macroseismic Scale, 1998). The historical center of Thessaloniki at the time of the earthquake consisted mainly of reinforced concrete buildings of six to nine stories height. A quantitative comparison between the fundamental frequency (fo) and the corresponding H/N amplitude level (Ao) versus the EMS_98 damage level is presented in Figure 11.

The higher levels of damage were observed at sites with low fundamental frequency and correspondingly intermediate $\mathrm{H} / \mathrm{V}$ amplitude level, while low levels of damage were observed at sites with high fundamental frequency and correspondingly low H/V amplitude level. 


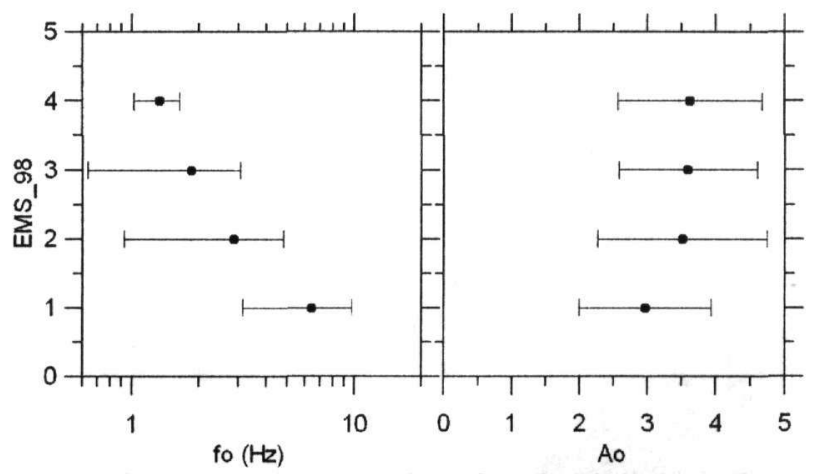

Figure 11. Correlation between fundamental frequency (fo) (left part) and corresponding average amplitude (Ao) (right part) with 4 damage grades of EMS-98 scale for the 1978 Thessaloniki earthquake.

In order to improve the correlation between the EMS_98 damage grades and the H/V amplitude level, we have also calculated the dynamic amplification of the buildings (Ubuilding) at the fundamental soil frequency (fo):

$$
U(f o)=\frac{1}{\sqrt{\left(1-\frac{T_{0}^{2}}{T^{2}}\right)^{2}+\frac{4 \zeta^{2} T_{0}^{2}}{T^{2}}}}
$$

where $T$ is the fundamental period of vibration and can be expressed as $T=$ number of storeys $/ 10$.

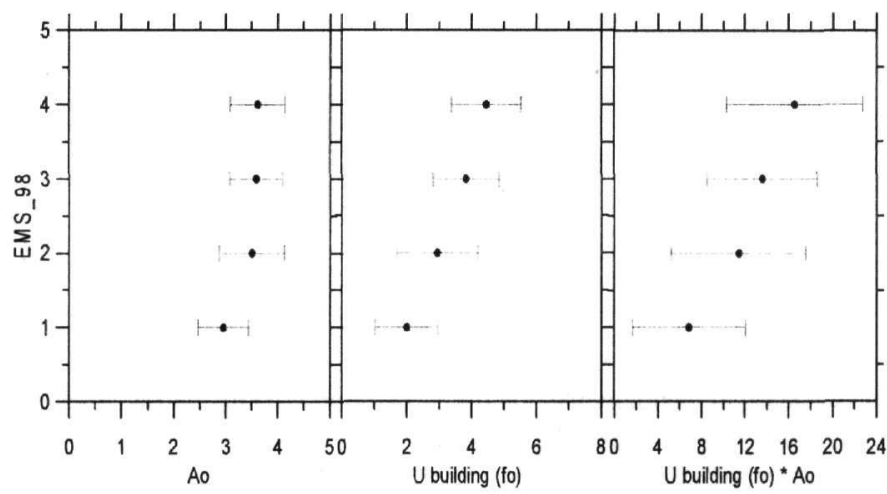

Figure 12. Correlation the EMS_98 damage grades from the 1978 Thessaloniki earthquake and the HN amplitude level (Ao) (Left part) with the Ubuilding(fo) (Center part) and versus Ubuilding(fo)*Ao (Right part).

In Figure 12 the comparison of the EMS_98 values versus H/V amplitude level (left), versus Ubuilding(fo) (center) and versus Ubuilding(fo ${ }^{\star} A \circ$ (right), is shown. It can be observed that the best correlation is found between EMS_98 and Ubuilding(fo)*Ao.

\section{CONCLUSIONS}

The objective of this study was to examine the reliability and validity of the HVSR_AM technique in site characterization in urban environment, taking as a test area the city of Thessaloniki (Northern Greece). For this purpose we performed reliability tests and also we examined any probable correlation of the H/V SR_AM with observed intensities from the 1978 earthquake. The following results were obtained: 
1. The HVSR_AM recordings at selected sites within the city of Thessaloniki were found to be in good agreement with respective results from previous studies using the $H / V$ receiver function technique.

2. The HVSR_AM in both horizontal components were found to be similar in terms of shape, the corresponding fundamental frequency but not in the amplitude level.

3. The study of diurnal variation of HVSR_AM suggested that it is preferable to perform ambient noise measurements during the calm hours of a day, when man made noise within urban environment does not exceed a desirable level.

4. It was observed that for the city of Thessaloniki there is no systematic seasonal effect on HVSR_AM.

5. There is a clear systematic change both in the fundamental frequency (fo) and the corresponding amplitude level (Aoew and Aons) obtained from the HVSR_AM, which is in relation with the thickness of the soil deposits.

6. Both the fundamental frequency (fo) and the H/V amplitude level (Aoew and Aons) obtained from the HVSR_AM correlated with the macroseismic intensity data and EMS 98 damage grades of the 1978 earthquake.

These results demonstrate the reliability and also the utility of the HVSR technique based on the recording of ambient noise, in order to provide important data on the seismic behavior of surficial layers. Based on them, HVSR_AM can be used as an inexpensive and fast tool in microzonation studies in urban environments.

\section{AGKNOWLEDGEMENTS}

The work reported here has been performed within the framework of the "SESAME" project, supported by the Environment and Sustainable Development Program of the European Commission Research Directorate General (EVG1-CT-2000-00026).

\section{REFERENCES}

Alfaro, A., Pujades L. G., Goula, X., Susagna, T., Navarro, M., Sanchez, J., and Canas A. (2001), Preliminary map of soil's predominant periods in Barcelona using Ambient noises, Pure Appl. Geophys. 158, 24992511.

Anastasiadis, A., Raptakis, D., Pitilakis, K., (2001), Thessaloniki's Detailed Microzoning: Subsurface Structure Site Response Analysis, Pure Appl. Geophys. 158, 2597-2633.

Bahavar, M., and North, R. (2002), Estimation of Background Noise for International Monitoring System Seismic Stations, Pure Appl. Geophys. 159, 911-944.

Bard, P.-Y. (1999), Ambient noise Measurements: A tool for site effect estimation?, In The Effects of Surface Geology on Seismic Motion, (ed. Irikura, Kudo, Okada and Sasatani) (Balkema, Rotterdam, 1999) pp. 1251 1279.

Bour, M., Fouissac, D., Dominique, P., and Martin, C. (1998), On the use of ambient noise recordings in seismic microzonation, Soil Dyn. Earthq. Eng. 17, 465-474.

Chatelain, J.-L., Gueguen, Ph., Guillier, B., Frechet, J., Bondoux, F., Sarrault, J., Sulpice, P., and Neuville J.-M. (2000), Cityshark: A user-friendly instrument dedicated to ambient noise (ambient noise) recording for site and building response studies, Seismol. Res. Lett. 71, 698-703.

Chávez-García, F. J., and Cuenca, J. (1996), Site effects in Mexico City urban zone. A complementary study, Soil Dyn. Earthq. Eng. 15, 141-146.

Delgado, J., López Casado, C., Giner, J., Estévez, A., Cuenca, A., and Molina, S. (2000a), Microtremors as a Geophysical Exploration Tool: Application and Limitations, Pure Appl. Geophys. 158, 2525-2541.

Delgado, J., López Casado, C., Estévez, A., Giner, J., Cuenca, A., and Molina, S. (2000b), Mapping soft soils in the Segura river valley (SE Spain): a case study of microtremors as a exploration tool, J. Appl. Geophys. 45, 19-32.

Duval, A.-M., Bard P.-Y., Meneroud J.-P., and Vidal, S. (1995), Usefulness of ambient noises measurements for site effects, Proc. of 10th European Confer. on Earthquake Engineering, Vienna, Austria, pp. 521-528.

European Macroseismic Scale, 1998, http://www.gfz-potsdam.de/pb5/pb53/projekt/ems.

Field, E., and Jacob, K. (1993), The theoretical response of sedimentary layers to ambient seismic noise, Geophys. Res. Lett. 20-24, 2925-2928. 
Fyen J., (1990), Diurnal and seasonal variations in the microseismic noise level observed at the NORESS array, Phys. Earth Plan. Inter. 63, 252-268.

Gitterman, Y., Zaslavsky, Y., Sharipa, A., and Shtivelman, V. (1996), Empirical site response evaluations: case studies in Israel, Soil Dyn. Earthq. Eng. 15, 447-463.

Havskov, J., and Ottemöller, L. (2000), SEISAN: The Earthquake Analysis Software, Report of Inst. Solid Earth Physics, Univ. Bergen (Bergen, Norway 2000).

Konno, K., and Ohmachi T. (1998). Ground-motion characteristics estimated from spectral ratio between horizontal and vertical components of ambient noise, Bull. Seism. Soc. Am. 88, no. 1, 228-241.

Lachet, C., and Bard, P.-Y. (1994), Numerical and Theoretical Investigations on the Possibilities and Limitations of Nakamura's Technique, J. Phys. Earth. 42, 377-397.

Lachet, C., Hatzfeld, D., Bard, P.-Y., Theodoulidis, N., Papaioannou, Ch., and Savvaidis, A. (1996), Site Effects and Microzonation in the city of Thessaloniki (Greece): Comparison of Different Approaches, Bull. Seismol. Soc. Am. 86, 1692-1703.

LeBrun, B., Hatzfield, D. and Bard, P.-Y. (2001), Site effect study in urban area: Experimental results in Grenoble (France), Pure Appl. Geophys. 158, 2543-2557.

Leventakis, G.-A., (2003). Microzonation Study of the city of Thessaloni, PhD., Aristotle University of Thessaloniki: $84 \mathrm{pp}$ (in Greek with an English abstract).

Lermo, J. and Chávez-Garcia, F. J. (1994), Are Ambient noise Useful in Site Response Evaluation?, Bull. Seismol. Soc. Am. 84, 1350-1364.

Milana, G., Barba, S., Del Pezzo, E., and Zambonelli, E. (1996), Site Response from Ambient Noise Measurements: New Perspectives from an Array Study in Central Italy, Bull. Seismol. Soc. Am. 86, 320-328.

Mucciarelli M., (1998), Reliability and Applicability of Nakamura's technique using Ambient noises: An experimental approach, J. Earthq. Eng. 2, 625-638.

Nakamura, Y. (1989), A method for dynamic characteristics estimation of Osubsurface using ambient noise on the ground surface, QR Railway Tech. Res. Inst. 30, 25-33.

Navarro, M., Enomoto, T., Sánchez, F. J., Matsuda, I., Iwatate, T., Posadas, A. M., Luzón, F., and Seo, K. (2001), Surface soil effects study using short-period Ambient noises observations in Almeria City, Southern Spain, Pure Appl. Geophys. 158, 2481-2497.

Nogoshi, M. and Igarashi, T. (1971), On the Amplitude Characteristics of Ambient noise (Part 2), J. Seismol. Soc. Japan 24, 26-40.

Ohta, Y., Kagami, H., Goto, N., and Kudo, K. (1978), Observations of 1-5second ambient noise and their application to earthquake engineering. Part I: Comaparison with long-period accelerations at the Tokachi-Oki earthquqke of 1968, Bull. Seismol. Soc. Am. 68, 767-779.

Ojeda, A., and Escallon, J. (2000), Comparison between different techniques for evaluation of predominant periods using strong ground motions records and microtremors in Pereira Colombia, Soil Dyn. Earthq. Eng. $20,137-143$.

Parolai S., Bormann, P., and Milkereit, C., (2002), New relationships between Vs, Thickness of Sediments and Resonance frequency calculated by the H/N ratio of seismic noise for the Cologne area (Germany), Bull. Seism. Soc. Am. 92, 2521-2527.

Penelis G., Stylianidis K., Stavrakakis E., 1985. Statistical evaluation of the response of the buildings in the center of Thessaloniki to the earthquake of 20 June $1978,12^{\text {th }}$ regional Seminar on Earthquake Engineering.

Rodriguez, V. H. S. and Midorikawa S., (2002). Applicability of the HN spectral ratio of ambient noises in assessing site effects on seismic motion, Earthq. Eng. and Structural Dynamics 31, 261-279.

SESAME Project 2003, Site EffectS assessment using AMbient Excitations, http://sesame-fp5.obs.ujfgrenoble.fr.

Suzuki T., Adachi Y., Tanaka M., (1995), Application of ambient noise measurements to the estimation of earthquake ground motions in Kushiro city during the Kushiro-Oki earthquake of 15 January 1993, Earthq. Eng. Struct. Dyn. 24, 595-613.

Teves-Costa, P., Matias, L., Bard, P.-Y. (1996), Seismic behaviour estimation of thin alluvium layers using ambient noise recordings, Soil Dyn. Earthq. Eng. 15, 201-209.

Toshinawa, J., Taber, J., and Berril, J. (1997), Distribution of ground-motion intensity from questionnaire survey, earthquake recordings, and microtremor measurements - A case study in Christchurch, New Zealand, during the1994 Arthus Pass earthquake, Bull. Seism. Soc. Am. 87, 356-369.

Triantafyllidis, P., Hatzidimitriou, P., Theodoulidis, N., Suhadolc, P., Papazachos, C., Raptakis, D., and Lontzetidis, K. (1999), Site Effects in the city of Thessaloniki (Greece) estimated from acceleration data and 1D local soil profiles, Bull. Seism. Soc. Am. 89, 521-537

Tsilingiridis, G., Zachariadis, Th., and Samaras, Z., (2002), Spatial and temporal characteristics of air pollutant emissions in Thessaloniki, Greece: investigation of emission abatement measure, Sc. Total Environ. 300 , $99-113$ 